\title{
Paeonia Türlerinin Antibakteriyal Aktivitesi
}

\author{
Kenan Tunç, Dilek İnceçayir, Vusale Mammadova, Alican Bahadır Semerci* \\ Sakarya Üniversitesi, Fen Edebiyat Fakültesi Biyoloji Bölümü, Serdivan/Sakarya.
}

$\ddot{\mathbf{O} z}$

Bu çalışmada Paeonia peregrina, Paeonia mascula subsp. mascula ve Paeonia tenuifolia'nın antibakteriyel aktivitesinin belirlenmesi amaçlanmıştır. Türkiye'de geniş yayılış alanlarına sahip Paeonia türleri Yalova Atatürk Bahçe Kültürleri Merkez Araştırma Enstitüsü'nden temin edilmiştir. Kök ve yapraklarından metanol, etanol, aseton, hekzan çözücüleri kullanılarak ekstraktlar elde edilmiştir. Elde edilen ekstraktların Bacillus subtilis ATCC 6633, Escherichia coli ATCC 8739, Enterecoccus faecalis ATCC 29212, Staphylococcus aureus ATCC 29213, Staphylococcus epidermidis ATCC 12228 ve Salmonella typhimurium ATCC 14028 suşları üzerine disk difüzyon yöntemi ile antibakteriyal etkileri incelenmiştir. Paeonia türlerinin yaprak ekstraktlarında en iyi çözücünün aseton olduğu ve Paeonia peregrina aseton ile hazırlanan ekstraktın $S$. aureus bakterisi üzerinde 17,3 mm inhibisyon zonu oluşturduğu belirlenmiştir. Paeonia türlerinin patojenlerin neden olduğu hastalıkların tedavisinde bazı sentetik antibiyotiklere alternatif olarak kullanılabileceği gösterilmiştir.

Anahtar kelimeler: Antimikrobiyal aktivite, Paeonia, Disk difüzyon, Doğal ekstrakt

\section{Antibacterial activity of Paeonia species}

\begin{abstract}
The aim of this study was to determine the antibacterial activity of the Paeonia peregrina, Paeonia tenuifolia ve Paeonia mascula subsp. mascula. Paeonia species that also have widespread dissemination in Turkey were collected from Yalova Atatürk Horticultural Central. Extracts were obtained from the root and leaf parts using methanol, ethanol, acetone, hexane solvents. The antibacterial effect of the obtained extracts was examined by disk diffusion method on Bacillus subtilis ATCC 6633, Escherichia coli ATCC 8739, Enterecoccus faecalis ATCC 29212, Staphylococcus aureus ATCC 29213, Staphylococcus epidermidis ATCC 12228 and Salmonella typhimurium ATCC 14028. It was determined that the best solvent in the Paeonia species leaf extracts was acetone and that the extract prepared with acetone produced a $17,3 \mathrm{~mm}$ inhibition zone diameter in $S$. aureus bacteria. It was demonstrated that Paeonia species can be used as an alternative to some synthetic antibiotics in the treatment of diseases caused by pathogens.
\end{abstract}

Keywords: Antimicrobial activity, Paeonia, Disc diffusion, Natural extract

\section{Giriş}

Sentetik kökenli ilaçların yan etkilerinin fazla olması ve antimikrobiyal olarak kullanılan sentetik ilaçlara karşı organizmaların direnç geliştirmesi günümüzün en önemli sorunlarındandır. Bu

\footnotetext{
${ }^{*}$ Sorumlu Yazar: ORCID ID: orcid.org/ 0000-0001-9502-9321

Received: 15.11 .2018

e-mail: alicannn5434@gmail.com

Accepted: 06.01.2019
} 
durum da, sentetik antimikrobiyallere alternatif olarak doğal bitkisel kaynakların kullanılmasının önemini arttırmıştır [1].

Tüm dünya ülkelerinde olduğu gibi, Türkiye'de de tıbbi açıdan önemli bitkiler yüzyıllardan beri halk arasında hastalıkların tedavisinde kullanılmaktadır. Dünya Sağlık Örgütünün (WHO) 91 ülkenin farmokopeleri, tıbbi bitkiler ile ilgili yayınlara dayanarak hazırlamış olduğu bir araştırmaya göre, tedavi amaciyla kullanılan tıbbi bitkilerin toplam sayısının 20.000 olduğu bildirilmiştir $[2,3]$.

Türkiye'de ayı gülü olarak bilinen Paeonia çok y1llık, otsu ve rizomlu bir bitkidir. Bocur, gülora, eşekgülü, şakayık, yer şakağıyı gibi çeşitli adlarla tanınmaktadır. Kültür türleri bahçelerde süs bitkisi olarak yetiştirilmektedir. Pembe ve kırmızı çiçekli olanları geniş yayılış alanına sahiptir $[4,5,6]$.

Fenolik bileşikler [7], monoterpen glikozitler [8] açısından zengin olan Paeonia türleri üzerine birçok farmasötik çalışma yapılmıştır. Çiçekleri (Flores paeonia) ve kökleri (Radix paeonia) epilepsi, boğmaca öksürüğünde yatıştırıc1, sedatif ve spazmolitik, mikrop öldürücü, kanı temizleyici, kalp, mide ve bağırsak rahatsızlıklarını tedavi edici olarak kullanılır $[9,10]$.

$\mathrm{Bu}$ çalışmada Paeonia peregrina,
Paeonia tenuifolia ve daha önce literatürde antibakteriyel çalışması bulunmayan Paeonia mascula subsp. mascula'nın antibakteriyel aktivitelerinin belirlenmesi amaçlanmıştır.

\section{Materyal ve Yöntem}

Bitki Materyali

Araştırmada kullanılan Paeonia peregrina L., Paeonia tenuifolia L. ve Paeonia mascula (L.) Mill. subsp. mascula örnekleri Yalova Atatürk Bahçe Kültürleri Merkez Araştırma Enstitüsü'nden toplanmıştır. Gölgede kurutulan bitki kısımları aseptik koşullarda ayrı ayrı ögütülerek toz haline getirilmiştir.

\section{Bitkisel Özütlerin Hazırlanması}

Ögütülmüş bitki örnekleri $10 \mathrm{~g}$ olacak şekilde hassas terazide tartılarak ayrı ayr1 $100 \mathrm{~mL}$ metanol (MERCK), etanol (MERCK), aseton (MERCK) ve hekzan (MERCK) içerisine eklenmiştir. Karanlık ortamda $25^{\circ} \mathrm{C}$ 'de 72 saat bekletilen ekstraktlar maserasyon yöntemine göre hazırlanmıştır. İşlem sonunda özütler filtre kâğıdından (Whatman) süzülmüş ve elde edilen ekstraktaki çözücüler rotary evaporatör (Heidolph laborota 4000 efficient) ile uzaklaştırılmıştır. Elde edilen ham ekstraktlardan $\left(6400 \mu \mathrm{g} \mathrm{mL}^{-1}\right) 6 \mathrm{~mm}$ çapındaki boş steril disklere $10 \mu \mathrm{L}$ emdirilerek 24 saat karanlık steril ortamda 
bekletilmiștir.

\section{Bakteri Suşlarının Temini}

Çalışmada

kullanılan

mikroorganizmalar Sakarya Üniversitesi Fen Edebiyat Fakültesi Biyoloji Bölümü Mikrobiyoloji Araştırma Laboratuvarı suş koleksiyonundan temin edilmiştir. Çalışmada Bacillus subtilis ATCC 6633, Escherichia coli ATCC 8739, Enterecoccus faecalis ATCC 29212, Staphylococcus aureus ATCC 29213, Staphylococcus epidermidis ATCC 12228 ve Salmonella typhimurium ATCC 14028 bakterileri kullanılmıştır.

\section{Disk difüzyon yöntemi}

Ekstraktların

antibakteriyel

aktivitesi disk difüzyon yöntemi kullanılarak belirlenmiştir [11]. Aktifleştirilen taze kültürlerin konsantrasyonu ortalama 0,5 McFarland $\left(1 \times 10^{8} \quad \mathrm{CFU} \quad \mathrm{mL}^{-1}\right)$ olacak şekilde ayarlanmış ve steril eküvyon çubuk ile Müeller Hinton Agara (MERCK) ekimi yapılmıştır. Bakteri ekimi gerçekleştirilen Müeller Hinton Agara aseptik koşullarda pens yardımıyla eşit mesafede ekstrakt emdirilmiş diskler yerleştirilmiştir. $37^{\circ} \mathrm{C}$ 'de 24 saat inkübe edilmiştir. İnkübasyon sonucunda disk etrafında o patojene karşı bir inhibisyon zonu oluşmuşsa petrinin arka kısmından dijital kumpas yardımıyla zon çapları (mm) ölçülmüştür. Tüm çalışmalar üç tekrarlı olarak gerçekleştirilmiştir. Pozitif kontrol olarak Gentamicin, negatif kontrol olarak ekstraktın hazırlandığ 1 çözücü kullanılmıştır.

\section{Bulgular}

Paeonia türlerinin kök ve yapraklarından hazırlanan ekstraktların test mikroorganizmalarına karşı oluşturdukları inhibisyon zon çapı ölçümleri Tablo 1'de verilmiştir. $P$. peregrina yaprağı ile hazırlanan aseton ekstraktın $S$. aureus üzerinde $17,3 \mathrm{~mm}, P$. mascula subsp. mascula köküyle hazırlanan etanol ekstraktın $E$. coli üzerinde $12,2 \mathrm{~mm}$ inhibisyon zon çap1 oluşturduğu belirlenmiştir. $P$. tenuifolia metanol ekstraktının E. coli ve E. faecalis bakterileri üzerinde 15,1 $\mathrm{mm}$ inhibisyon zon oluşturduğu tespit edilmiştir. Deney sonuçlarına göre ekstraktların gösterdiği en yüksek inhibitör etkinin $S$. aureus ve $E$. coli suşları üzerinde olduğu gözlenmiştir. Kullanılan bitkilerin antibakteriyel etkileri kıyaslandığında sıralamanın $P$. peregrina > P. tenuifolia $>$ P. mascula subsp. mascula şeklinde olduğu görülmektedir. Hekzan çözücüsüyle hazırlanan ekstraktlarda sonuç alınamamıştır. 
Tablo 1. Paeonia ekstraktlarının test bakterileri üzerinde oluşturdukları inhibisyon zon çapları

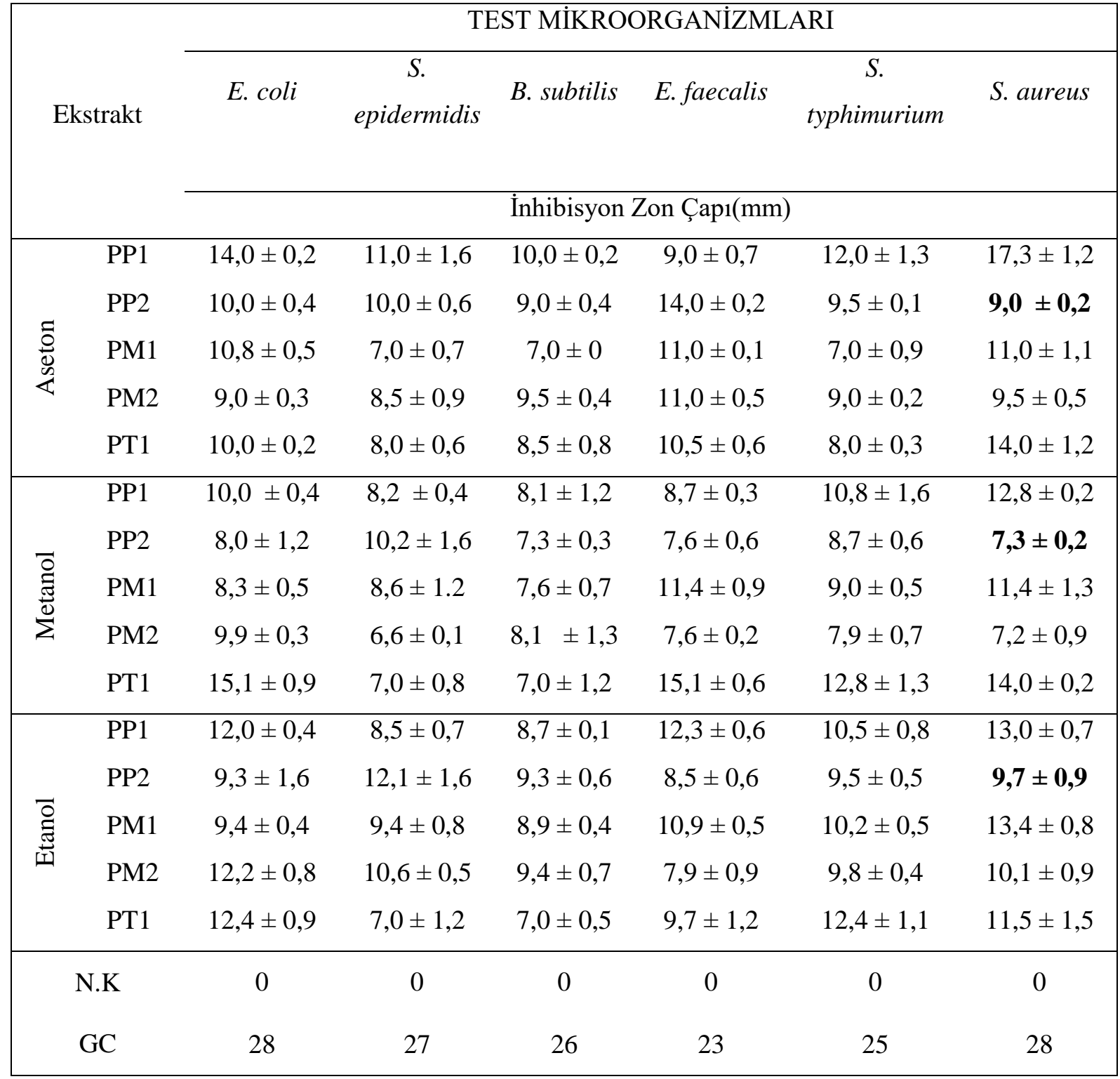

Hekzan çözücülerinden sonuç alınamamıştır.

PP1: Paeonia peregrina yaprak, PP2: Paeonia peregrina kök, PM1:Paeonia mascula subsp mascula yaprak, PM2: Paeonia mascula subsp mascula kök, PT1: Paeonia tenuifoli yaprak, N.K.: Negatif Kontrol, GC: Gentamicin, \pm : standart sapma değeri

\section{Tartışma ve Sonuç}

Son y1llarda insan, hayvan sağlığının patojen mikroorganizmalara karşı korunmasına yönelik ve gıdalarda bozulmaya neden olan mikroorganizmaların varlığına karşı geleneksel yaklaşımlardaki gelişmelere paralel olarak antimikrobiyal aktivite ile ilgili araştırmalar ve bitki uçucu yağlarının potansiyel kullanımı ön plana çıkmıştır. Bu 
nedenle, farklı patojenlere karşı bitki ekstraktlarının antimikrobiyal aktivitesi üzerine yapılan araştırmalar dünya çapında yaygınlık kazanmıştır [12].

Paeonia cinsi üzerinde $\mathrm{Wu}$ ve ark. [13] tarafindan kimyasal içerik ve biyoaktivite çalışmaları yapılmış ve 13 monoterpen, 45 monoterpen glikozit, 22 triterpenoid, 8 flavonoid, 26 fenol ve fenolik glikozit, 31 tanen elde edildiği bildirilmiştir. Paeonia cinslerinin antioksidatif, antikoagülan ve antiagregan, antienflamatuvar, sedatif ve analjezik gibi birçok etkisi olduğu belirtilmiştir. Başka bir çalışmada Paeonia türlerinin esansiyel yağları analiz edilmiştir. Salisilaldehit, cismirtanal ve metil salisiyitatın ana bileşenler olarak yer aldığı ve bileşimde birçok yağ asidini içerdiği belirlenmiştir [14]. Paeonia türlerinin içerdiği yağ asitleri, terpenler ve fenolik maddeler gibi sekonder metabolitlerden dolayı antibakteriyal aktivite gösterdiği düşünülmektedir.

Bu çalışmada $P$. peregrina ve $P$. tenuifolia ham ekstraktlarının $S$. epidermidis ve $S$. aureus'un üremesini yüksek oranda inhibe ettiği görülmüştür. Ivanova ve ark. [15] çalışmamızdakine benzer şekilde $P$. peregrina ve $P$. tenuifoli 'nın köklerinden elde edilen asidik fraksiyonları S. aureus, $E$. coli ve $C$. albicans mikroorganizmalarına karş1 antimikrobiyal etkilerini incelemiş ve tüm fraksiyonların $S$. aureus üzerinde etkili olduğu bildirilmiştir.

Kunduhoğlu ve ark. [16] yaptıkları çalışmada Eskişehir bölgesinden topladıkları $P$. peregrina yapraklarından sokslet yöntemini kullanarak ekstraktlar hazırlamışlardır. Hazırlanan ekstraktın $B$. subtilis'te $11 \mathrm{~mm}, S$. aureus'ta $9 \mathrm{~mm}, S$. epidermidis'te $11 \mathrm{~mm}$, E. coli'de $8 \mathrm{~mm}$ inhibisyon zonu oluşturduğu görülmüştür. Çalışmamızda $P$. peregrina yaprağının aseton ile hazırlanan ekstraktının $B$. subtilis 'te $10 \mathrm{~mm}$, S. epidermidis 'te $11 \mathrm{~mm}$, E. coli'de $14 \mathrm{~mm}$ ve $S$. aureus'ta $17,3 \mathrm{~mm}$ inhibisyon zon çap1 oluşturduğu belirlenmiştir. İki çalışma arasındaki farklılık ekstrakt hazırlama yöntemlerinden olabileceği gibi bitkilerin toplandıkları bölgenin toprak içeriği, iklim şartları gibi etmenlerden de kaynaklanabilir.

Soare ve ark. [17] çalışmamızdakine benzer şekilde $P$. officinalis'den etanol ve metanol çözücüleriyle yaptıkları ekstraktların antibakteriyal etkisini araştırmışlardır. Etanol ile hazırlanan ekstraktın E. faecalis üzerinde $14,5 \mathrm{~mm} E$. coli bakterisi üzerinde ise $16,5 \mathrm{~mm}$ inhibisyon zon oluşturduğunu bildirmişlerdir. Çalışmamızda ekstraktların antimikrobiyal aktivitesi pozitif kontrol olan Gentamicinle kıyaslandığında 
kullanılan ekstraktların test bakterileri üzerinde orta derecede antibakteriyel etki gösterdiği belirlenmiştir. Ayrıca P. mascula subsp mascula'nin kullanılan test mikroorganizmalarına karşı antibakteriyel etkisinin olduğu ilk kez bu çalışmada belirlenmiştir. Kullanılan çözücülerin bitki içeriğinin açığa çıkarılmasında önemli olduğu gözlenmiştir. Paeonia türleri içerisinde $P$. peregrina'dan aseton ile hazırlanan ekstraktının önemli düzeyde antibakteriyal etkiye sahip olduğu tespit edilmiştir. $P$. peregrina'dan elde edilen ekstraktın birçok antibiyotiğe karşı direnç geliştiren $S$. aureus bakterisi üzerinde yüksek oranda inhibisyon etkisinin olmas1 dikkat çekicidir. Paeonia türleri patojenlerin neden olduğu hastalıkların tedavisinde bazı sentetik antibiyotiklere alternatif olarak kullanılabileceğini göstermiştir.

Yapılan bu tip çalışmaların yaygınlaştırılarak bitkilerin etken maddelerinin izole edilip tanımlanmasının tıpta, gıda sektöründe ve endüstride kullanım olanakları açısından önemli bir olgu olabileceğini düşünmekteyiz.

\section{Kaynaklar}

[1] Bayaz, M. 2014. Esansiyel Yağlar: Antimikrobiyal, Antioksidan ve Antimutajenik Aktiviteleri. Akademik Gida, 12(3) 45-53.
[2] Dağçı, K. E. İzmirli, M., Dığrak, M. 2002. Kahramanmaraş İlinde Yetişen Bazı Ağaç Türlerinin Antimikrobiyel Aktivitelerinin Araştırılması, KSÜ Fen ve Mühendislik dergisi, 5(1).

[3] Aydın, B. 2008. Bazı Tıbbi Bitki ve Baharatların Gıda Patojenleri Üzerine Antibakteriyel Etkisinin Araştırılması, Kafkas Üniv Vet Fak Derg. 14 (1): 83- 87.

[4] Gök, T.A. 2006. Kırda Bayırda Gezginin Cep Kitabı. Kaknüs Yayınları, İstanbul.

[5] Çiçek, A. Koyuncu, O. Yaylacı, K. 2014. Seyitgazi Ovasının Çiçekleri. Anadolu Üniversitesi Yayınları; NO 3056. Çevre sorunları Uygulama ve Araştırma Merkezi Yayınları ; NO. 4, 60- 66.

[6] Melikoğlu, G. Kurtoğlu, S., Kültür, Ş. 2015. Türkiye'de Astım Tedavisinde Geleneksel Olarak Kullanılan Bitkiler. Marmara Pharmaceutical Journal. 19: 1-11.

[7] Zhang, X., Shi, Q., Ji, D., Niu, X.L., Zhang, Y.L., 2017. Determination of the phenolic content, profile, and antioxidant activity of, seeds from nine tree peony (Paeonia section Moutan DC.) species native to China, Food Research International 97 s.141-148.

[8] He, C., Peng, Y., Xiao, W., Liu, H. ,Xiao, P., 2012. Determination of chemical variability of phenolic and monoterpeneglycocides in the seeds of paeonia species using HPLC and profiling analysis, Food Chemistry. 138: 2108-2114.

[9] Leporattia, M., Ivancheva, S., 2003. Preliminary comparative analysis of medicinal plants used in the traditional medicine of Bulgaria and Italy, Journal of Ethnopharmacology 87: 123-142. 
[10] Dindaroğlu, T., 2014. Şakayık Bitkisinin (Paeonia mascula) Bazı Ekstrem Yetişme Ortamı III. Uluslararası Odun Dış1 Orman Ürünleri Sempozyumu 8-10 Mayıs 2014, Kahramanmaraş.

[11] National Committee for Clinical Laboratory Standards (NCCLS, 1997)

[12] Teles-Andrade, B.M.F., Lidiane, N.B. Silva Probst, I., Fernandes Júnior, A., 2014. Antimicrobial activity of essential oils, Journal of Essential Oil Research, 26:1, 3440 .

[13] Wu, S.H., Wu D, Chen Y.W, 2010. Chemical Constituents and Bioactivities of Plants from the Genus Paeonia Chemistry \& Biodiversity - Vol. 7.

[14] Orhan, İ., Demirci, B., Omar, I., Siddiqui, H., Kaya, E., Choudhary, M., Ecevit-Genç, G., Özden, 2004. Farmasötik Kimya Pratikleri, Ankara Üniversitesi Eczacılık Fakültesi Yayınları, Ankara.

[15] Ivanova, A., Delcheva, I., Tsvetkovab, I., Kujumgievb, A., and Kostova, I., 2002. GC-MS Analysis and Anti-Microbial Activity of Acidic Fractions Obtained from Paeonia peregrina and Paeonia tenuifolia Roots. Naturforsch, 57s. 624-628.

[16] Kunduhoğlu, B., Platin, S., Çalışkan, F., 2011. Antimicrobial Screening Of Some Medicinal Plants Collected From Eskisehir, Turkey. Fresenius Environmental Bulletin (20):4 945-952.

[17] Soare, L.C., Ferde, M., Stefanov, S., Denkova, Z., Nicolova, R., Denev, P., Ungureanu, C., 2012. Antioxidant and Antimicrobial Properties of some Plant Extracts. REV. CHIM. (Bucharest) 63 No.4. 